\title{
Malingering mental disorders: medicolegal reporting
}

\author{
Keith J. B. Rix \& Derek K. Tracy
}

\begin{abstract}
SUMMARY
In this second part of a two-article review on malingering we consider the challenges of presenting clinical and psychometric findings. Numerous clinical and demographic factors are statistically associated with malingering but applying them to an individual case risks challenges to the expert psychiatric witness's evidence. Although psychometric data can usefully help strengthen or challenge a diagnosis, expert witnesses must recognise and report the limitations of these tests. We recommend that psychiatric expert witnesses do not try to look for or to link any external incentives with clinical findings, and indeed we suggest that they should, other than exceptionally, avoid using the term 'malingering'. It is the job of the court, not the expert witness, to ascertain an individual's credibility and motives. We suggest a framework for presenting expert psychiatric evidence in this area.
\end{abstract}

\section{LEARNING OBJECTIVES}

- Appreciate clinical and sociodemographic factors associated with malingering, and the challenges to applying these in individual cases

- Understand the legal scrutiny to which the reporting of psychometric data might be exposed

- Appreciate the roles of the expert witness and the court, and have a suitable framework for reporting expert psychiatric evidence in such cases

\section{DECLARATION OF INTEREST \\ None}

'Malingering assessments can be extremely challenging as malingering itself involves two opposite ends of the forensic spectrum: it is so easy to suspect, yet so difficult to prove' - Scott 8 McDermott (2011: p. 251)

This is the second of two articles on malingering mental disorder. In the first article (Tracy 2017) we explored the literature on epidemiology and clinically delineated 'typical' and 'atypical' (and, putatively, 'malingered') symptomatology for a range of conditions. We also addressed the general challenges of clinical assessments where malingering is suspected or detected, and described the varying utility of psychometric tests. In this second article we will describe the challenges of presenting clinical and psychometric findings in a medicolegal environment (illustrated with three recently reported cases), delineate the roles of the medical expert and the court, and propose a model for reporting of findings.

\section{Presenting findings - the challenges}

Millis \& Putnam (1996) noted three factors that can limit the detection of malingering: a false clinical perspective on one's ability to determine the likelihood of malingering once a clinical rapport has been established; the danger of an expert's confirmatory bias or attribution error leading to either over- or under-detection; and the limitation of solely utilising psychometric performance data. Work by Hickling et al (2002) has found that even 'highly experienced' clinicians had difficulty identifying actors simulating illness, and there is evidence (Hall 2006) that clinicians can be reluctant to label an individual as a malingerer for various reasons, including concerns about therapeutic relationships and fears of medicolegal consequences. There is thus the danger that such concerns could bias a clinician into adopting a 'safer' and more conservative position.

Both ICD-10 (World Health Organization 1992) and DSM-5 (American Psychiatric Association 2013) criteria for malingering are wide in scope. Slick et al (1999) proposed more specific guidelines, which have been endorsed by the American Academy of Clinical Neuropsychology in a consensus statement on malingering (Heilbronner 2009). However, these apply specifically to neurocognitive dysfunction, and their use in other cases of putative malingering of a mental illness is thus open to challenge. Furthermore, the first of Slick et al's criteria is the presence of a substantial incentive; although this is of course essential for malingering, we would argue that in a medicolegal setting it is not the role of the expert either to seek to identify such an incentive or to try link such with any real or possibly exaggerated or feigned psychopathology.

Incentives can be found in many instances, but no matter how substantial they are, they do not of themselves prove malingering, even if they are
Keith Rix is honorary consultant forensic psychiatrist with Norfolk and Suffolk NHS Foundation Trust, and Visiting Professor of Medical Jurisprudence at the University of Chester, where he is involved with its MSc in Medicolegal Practice. $\mathrm{He}$ is an elected Honorary Fellow of the Faculty of Forensic and Legal Medicine of the Royal College of Physicians. Derek Tracy is a consultant psychiatrist and the Associate Clinical Director for crisis, in-patient and rehabilitation services at Oxleas NHS Foundation Trust, London. He is a Biomedical Research Centre Research Fellow and runs MSc modules in psychopharmacology and mental health in the community at the Institute of Psychiatry, Psychology and Neuroscience, King's College London.

Correspondence Dr Derek K. Tracy, The Memorial Hospital, Shooter's Hill, London SE18 3RG. Email: derek.tracy@nhs.net

\section{Copyright and usage}

(c) The Royal College of Psychiatrists 2017. 
the individual's stated primary motivator. There are nascent data suggesting that the nature of the incentive will differentially motivate individuals: evidence of a desire for revenge and compensation (Peace 2011) and, in competency to stand trial cases, a more serious the alleged offence (especially murder and robbery) (McDermott 2013) were associated with greater rates of malingering. McDermott et al determined malingering rates of almost $65 \%$ in jailed inmates seeking psychiatric services (which was unrelated to their offence severity). This might represent a desire to move to a perceived improved environment, such as a healthcare wing. Overall, at present all these factors are at best of actuarial and population-level research interest and are of limited application in the individual case.

Malingerers have been shown to have statistically greater rates of personality disorders, substance misuse, employment difficulties and previous litigation, as well as fewer long-term financial responsibilities (Nies 1994; Lambert 1996). Specifically, antisocial personality disorder and antisocial traits are associated with a propensity to guiltless and socially irresponsible deception and exploitation (Black 2015), psychopathic traits with faking psychometric testing (Grieve 2012), and schizotypy with fantasy proneness and atypical psychometric data (Peace 2011). However, such factors are common, may be the consequence of true mental illness and are of little sensitivity or specificity in terms of detecting malingering.

\section{Psychometric testing in the courtroom}

Familiarity with this field of research, in particular the research set out in our previous article (Tracy 2017), is essential for the expert psychiatric witness who relies on psychometric testing. The Court of Appeal fired a warning shot in $R \mathrm{v}$ Dlugosz and Others [2013]:

'It is essential to recall the principle which is applicable, namely in determining the issue of admissibility, the court must be satisfied that there is a sufficiently reliable scientific basis for the evidence to be admitted. If there is then the court leaves the opposing views to be tested before the jury.'

Now, Part 19A (Expert Evidence) of the Criminal Practice Directions 2015, which supplements Part 19 (Expert Evidence) of the Criminal Procedure Rules 2015 (Statutory Instrument 2015 No. 1490), identifies a number of factors that the court may take into account in determining the reliability of expert opinion, including:

'if the expert's opinion relies on the results of the use of any method (for instance, a test, measurement or survey), whether the opinion takes proper account
B0X 1 The Daubert questions

Expert witnesses who rely on the results of psychometric testing might expect the following questions in crossexamination:

- Has the technique been tested in actual field conditions? Has the technique been subject to peer review and publication?

-What is the known or potential rate of error?

- Do standards exist for the control of the technique's operation?

- Has the technique been generally accepted within the relevant scientific community?

(Based on Daubert v Merrell Dow Pharmaceuticals (1993))

of matters, such as the degree of precision or margin of uncertainty, affecting the accuracy or reliability of those results;

the extent to which any material on which the expert's opinion is based has been reviewed by others with relevant expertise (for instance, in peerreviewed publications), and the views of others on that material;

[...]

whether the expert's methods followed established practice in the field and, if they did not, whether the reason for the divergence has been properly explained;

[...]

potential flaws in [the expert] opinion which detract from its reliability, such as:

being based on a hypothesis which has not been subjected to sufficient scrutiny (including, where appropriate, experimental or other testing), or which has failed to stand up to scrutiny;

[...]

relying on an examination, technique, method or process which was not properly carried out or applied, or was not appropriate for use in the particular case.'

(Criminal Practice Directions [2015]: parts 19A.5, 19A.6).

There is every reason to believe that, when the reliability of expert opinion is in question in other jurisdictions, the courts will have regard to these factors that are recommended for its testing in the criminal jurisdiction. Insofar as these developments reflect a move closer to the US approach to the admissibility of scientific evidence as set out in Daubert v Merrell Dow Pharmaceuticals (1993), Box 1 sets out the Daubert questions that the expert who relies on psychometric testing might expect on cross-examination. Also, as Dr Peter Ellis of 7 Bedford Row Chambers noted when referring to evidence based on clinical practice guidelines:

'Cross-examination of the expert may extend to the scope of the [tests], their development [...] known 
exceptions to their application, and whether any responsible body of medical thought recommends a different approach' (P. Ellis, personal communication, 2016).

\section{The role of the expert, the role of the court}

A good expert psychiatric report should encapsulate all relevant clinical, social and psychometric factors, but it should be left to the court to utilise this information appropriately and draw any inferences it wishes regarding an individual's character and credibility. The danger for the expert psychiatric witness is of unevidenced supposition, and thereafter the risk of significant and appropriate legal challenges to their impartiality. In a court of law the ultimate arbiter of credibility is the judge or jury. As Justice Clarence Thomas said in the case of US $v$ Scheffer (1998), where the issue was the admissibility of polygraph testing:

'A fundamental premise of our criminal trial system is that "the jury is the lie detector" [...]. Determining the weight and credibility of witness testimony, therefore, has long been held to be the "part of every case [that] belongs to the jury, who are presumed to be fitted for it by their natural intelligence and their practical knowledge of men and the ways of men" [...].'

This is not just the situation in the USA. It was held in an English court that, except in cases where mental disorder affects the capability of a witness to give reliable evidence, "it is for the jury, with all the warnings from counsel and the court which the law requires, to decide whether or not that witness is giving reliable evidence' ( $R$ $v$ MacKenney [2004]). Judges often instruct juries in the following terms: 'Assessment of reliability, truthfulness, importance and weight of evidence is for the jury alone' (Judicial Studies Board 2010).

Similarly, in civil cases, and in other non-jury cases such as those heard by tribunals, the judge or the trier of the facts makes an assessment of the reliability of the witnesses, including the litigant. This is clearly evident in published judgments, where findings of fact are usually preceded by an analysis of the extent to which, if at all in some cases, the trier of the facts can rely on the evidence of a witness as to the facts in dispute. Albeit not a case where malingering itself was the issue, the Scottish child abuse case of $S F{ }_{V}$ Quarriers [2015] (Box 2) illustrates the perils for the expert who strays beyond the limits of their proper role in offering an opinion on the truthfulness of the litigant. In Scotland the person bringing a claim is a 'pursuer' and the person against whom the claim is brought is a 'defender'.

The fundamental feature of malingering is dishonesty. So, an opinion in the medicolegal
BOX 2 The judgment of the court in SF v Quarriers [2015]
The pursuer raised an action against the defenders in respect of historical physical and mental injuries, including dissociative amnesia, allegedly sustained while he was a resident in a care home run by the defenders. Despite the generally focused nature of the expert witness's examination, it was considered to be 'tainted by her seeking to continue to rely on "False Memory Syndrome" as at least one explanation for the pursuer's condition' and straying 'beyond the limits of what was the proper role of the expert in offering her view that (in effect) [the pursuer's] memories of abuse were false. This was exacerbated by what were considered gratuitous and unfair comment upon [the pursuer's] credibility and reliability'; the comment that 'he was "economical with the truth" - which she accepted under cross-examination was a euphemism for lying' was held to be 'particularly egregious in this respect'. In 'a similar pejorative vein' was 'her reference to "magical mechanisms" (albeit that the word "magical" was subsequently withdrawn by her) and her analogy of proving the existence of Dissociative Amnesia as being subject to the same requirements as "proving the existence of unicorns"'.

Other aspects of the expert's evidence were found to demand caution from the Court: in cross-examination she was considered extremely combative; she was held to be 'given to making sweeping assertions which she did not vouch, for example the assertion that there is no evidence for dissociative amnesia' and 'the assertion that "you don't forget abuse"'; and she 'made it clear that she simply did not accept the DSM V category of Dissociative Amnesia, albeit that formed a widely accepted international standard'. context that a litigant or witness is malingering will almost always come so close to usurping the role of the judge or jury in assessing their honesty that it is best avoided. Furthermore, although the term is sometimes used in courts of law and tribunals, there is no legal definition of malingering. Although malingering is to be found as a condition in DSM5 (American Psychiatric Association 2013), heed should be paid to the judgment of His Honour Judge Richard Seymour QC, sitting as a High Court judge, in Turner \& Turner $v$ Jordan $\&$ Motor Insurers Bureau [2010], where an issue that divided the experts, albeit that it was not material to any matter in dispute, was whether malingering was a 'psychological condition'. The judge noted the definition in DSM-IV-TR (American Psychiatric Association 2000) (and now in identical form in DSM-5), but held that:

"The verb "malinger" is an ordinary English word, defined in The New Shorter Oxford English Dictionary, 4th ed. 1993, as meaning "Pretend or exaggerate illness in order to escape duty or work".

The judge said of one of the experts that it was 'to her credit, as it seems to me, [that she] does not agree that malingering is a psychological condition'. He then observed:

\begin{abstract}
All the DSM-IV-TR definition of malingering appears to do is to expand the dictionary definition and to classify what is in fact dishonest behaviour as a psychological condition.'
\end{abstract}

There is a risk of miscommunication and confusion if the expert uses the term in the DSM 
sense and the courts use it in its ordinary, everyday sense. To opine, in effect, that a witness is dishonest not only risks usurping the role of the court, but it lays the expert open to potentially difficult crossexamination. How do you know that the claimant is dishonest? How do you distinguish between a dishonest intent and unconscious exaggeration? What is the evidence that the claimant is motivated by the incentive of obtaining financial compensation or other external gain? And the stakes are now higher; under section 57 of the Criminal Justice and Courts Act 2015, a claimant will not recover any damages if they are found to have been 'fundamentally dishonest' in relation to their claim, so for the claimant much more now depends on their counsel's success in discrediting, or disproving the evidence of, the expert witness who asserts that the claimant is dishonest.

\section{Two further illustrative cases}

Box 3 outlines a case (Ali $v$ Caton $\&$ Motor Insurers Bureau [2013]) in which evidence from symptom validity test (SVT) data had to be considered, but only as part of a welter of other evidence, in order to decide whether the claimant had been malingering. Notwithstanding evidence that the claimant was found to have knowingly underperformed in the medicolegal examinations, the court found in his favour and rejected the defendant's case that his claim was essentially fraudulent. The précis in Box 3 is necessarily very brief, and we strongly recommend that expert psychiatric and

\section{B0X 3 A précis of Ali v Caton \& Motor Insurers Bureau [2013]}

\section{The defendant's case}

Jubair Ali suffered a very severe brain injury as a result of a road traffic accident. The defendant submitted that Jubair had been consistently malingering and relied on the following

- after the accident, Jubair attended a further education college, which showed a level of cognitive functioning and motivation inconsistent with his case

- expert-administered psychometric tests consistently indicated that he was deliberately exaggerating his difficulties

- Jubair's performance was worse than that seen over a period of months in residential rehabilitation

- of his own volition and initiative, Jubair took and passed the UK citizenship test.

\section{The evidence}

All independent factual witnesses agreed that Jubair passing the citizenship test 'would be inconsistent with the view that they had otherwise formed of his abilities'. The expert witnesses were unable to determine his motivation, but agreed that he had not cooperated with the assessment process and had profoundly failed symptom validity testing (SVT), rendering all other test results unreliable. In their second joint report the neuropsychologists considered that his poor performance was reflective of exaggeration, but that 'he nonetheless probably had problems in the domains tested'. Dr Powell emphasised the need 'to give an opinion based on the "broad picture"', rather than focusing specifically on test results, specifically SVTs; Dr Walton was 'much more sceptical about the ability of clinicians to form a valid opinion in the presence of the psychometric data which indicates that Jubair has not been giving of his best in testing'.

\section{Judgment of Mr Justice Stuart-Smith}

The judge said that the evidence of the neuropsychologists was important. First, 'Jubair's profound and repeated failure' of the SVTs meant that it was unsafe to rely on the quantitative estimates of cognitive deficits, extending even to those tests administered very early on when, in his view, it was 'highly unlikely that Jubair would have formulated any idea of misrepresenting his abilities'. Second, on the joint neuropsychological evidence, it was probable that, on at least some occasions, Jubair had not merely failed to do his best, but had deliberately underperformed: this went to the wider question of whether Jubair was presenting a claim that should be regarded as essentially fraudulent. Third, he accepted the evidence of Dr Walton that Jubair could not be in the first percentile in respect of memory, as had been suggested by some of the tests, 'since that would render him virtually totally amnesic and unable either to function as he had on a day to day level', or to pass the citizenship test and the exams he passed at college. Fourth, he accepted without reservation that it would be inappropriate for a neuropsychologist confronted by the test results that existed in this case to found his opinion solely on the basis of those results, since they could not be shown to be reliable and were shown to be probably unreliable. The presence of reliable test results was useful but not determinative; their absence did not absolve clinicians or the court from reviewing all of the available evidence in order to form an opinion.

Taken overall, the evidence established that Jubair had, on occasions, 'knowingly underperformed in the context of medico-legal examinations'. However, even this finding needed to be taken in context: he had 'also shown extreme fatigue in the context of non-medico-legal medical appointments, where feigning would provide no obvious benefit; and his inability to remember names has not been confined to the medico-legal setting'. How did he pass the citizenship test? The judge considered it probable that 'he learned answers by rote and then struck very lucky indeed in the questions that came up'.

On this evidence the judge found inevitably that Jubair's cognitive deficit attributable to the accident was 'not accurately reflected in the various test results that had been recorded over the years'. However, it did not follow that Jubair had 'knowingly been feigning an exaggerated level of disability over the period since the accident'. He accepted the evidence of the witnesses who had 'rejected the possibility that Jubair could have deceived all those responsible for his care since the time of the accident'. He accepted that 'treating clinicians and support workers do not set out with the same level of forensic scepticism as may be appropriate in a medico-legal context', but he also accepted 'the evidence that clinicians will be alert to inconsistencies in behaviour that may indicate a lack of genuine presentation'. He was particularly influenced by the evidence from Jubair's time in rehabilitation: he considered it 'supremely unlikely that Jubair could have fooled all of those who gave him close and detailed care and attention during the $91 / 2$ months that he was resident there for five days a week'. He therefore found as a fact that this evidence provided 'a reliable picture of Jubair's genuine levels of functional ability to perform on a day to day level'. 
BOX 4 The judgment of Mr Justice David Clarke in Edwards v Martin [2010]

The claimant, a 41-year-old man, was involved several years previously in a road traffic accident, sustaining a severe and life-threatening head injury. Although he made a good physical recovery, it was common ground that there was a traumatic brain injury which resulted in 'a permanent loss of cognitive functioning and emotional and behavioural problems, properly diagnosed as an organic personality disorder'. Specifically, there was memory loss, fatigue, amotivation, lability of mood, concrete thinking and depression.

However, there was significant dispute between the parties as to how severe the neuropsychiatric problems were. Their severity had implications for resolving the issues of future care, capacity and residual employability. Surveillance was claimed to show the man engaged in various activities inconsistent with his purported disability. The defendant's neuropsychologist argued that there was no genuine neuropsychological reason that could explain the claimant's performance on some of the applied tests. In particular, on a number of occasions he performed 'more poorly on tests of recognition memory than on tests of free recall' and this was put forward as 'an abnormal finding in a case of genuine disability in this area. On two occasions, on a measure of visual memory, he performed at "below chance" levels', which, it was proposed, indicated knowledge of the correct response in order to answer incorrectly. Attention was also drawn to elements of the tests in which the claimant's performance deteriorated between one occasion of testing and the next, when there could be no organic reason for such a decline.

Conversely, the claimant's psychologist, under lengthy challenge in a sustained crossexamination, 'did not accept that a finding of deliberate exaggeration could be justified on the strength of psychometric testing alone. He stressed the importance of taking into account the lay evidence and other professionals' evidence as to the nature and extent of the disability'. He argued that there could be other explanations for inconsistencies in the results of psychometric tests. Although deliberate underperformance might be an explanation for some of the results, he noted that the claimant did not underperform in all the tests, and said that it would be highly unlikely that a person who was deliberately exaggerating would perform normally in tests of verbal memory as he did. The claimant was noted to have cooperated fully on all the other tests that were applied, not knowing what they were designed to measure, and some of the inconsistencies might have arisen from episodes of depression that the claimant was suffering at the time.

Particular attention was also given to the surveillance footage showing the claimant walking to the nearby park with three children, playing football and supervising them on swings in a relaxed and entirely normal manner. The children were relatives of his support worker.
The judgment was that there had been 'no conscious exaggeration on the claimant's part'. It was noted that he had 'shown little or no interest in this litigation at any time'. There was specific evidence of 'his lack of interest in, and carelessness with, his financial affairs'; for a long time 'he lacked insight into the extent of the effects of his injury upon his life and relationships. Early medical reports indicated that 'he tended to minimise his problems, or to be unaware of them' As to the surveillance material, it was accepted that it did 'nothing to undermine the main thrust of the claimant's case that the neuropsychiatric outcome of his head injury has been severe'. Rather, it was concluded that it demonstrated that he could 'perform these activities without needing carer support or supervision'. The judge stated that it was to the support worker's credit that the claimant was able to maintain contact with her children. There were repeated references in her reports to 'the importance of maintaining his social contacts and the goal of achieving social integration', and his undertaking enjoyed activities such as golf had played its part in the efforts made to achieve this goal.

The judge noted the defence expert witness's reliance on effort testing within the psychometric tests, and stated that she stood alone in expressing the view that the claimant consciously exaggerated his disability, and did so solely on the strength of the these tests. psychological witnesses read the full report of this case for an example of how expert evidence is used and tested in cases where malingering is an issue. ${ }^{a}$

Box 4 outlines a case in which SVT assessment was the focus of expert evidence. Although psychometric testing and surveillance footage were argued to be inconsistent with the claimant's purported disabilities - including 'below chance' test results on forced-choice SVTs - the judgment found in his favour, with criticism of the defendant's psychologist's reliance on psychometric testing.

\section{Discussion: a framework for reporting findings}

'Though this be madness, yet there is method in't' - Polonius, Hamlet, 2.ii.195-6

Eyre \& Alexander (2015: p. 180) advise medical experts:

'When dealing with cases where there is a suspicion of "Exaggeration" or "Malingering", an expert should first define how these terms are being used in the report or avoid their use altogether, as neither has a legal definition.'
We suggest that the expert psychiatric witness should altogether avoid the use of the term malingering. Therefore, we propose an alternative framework (Fig. 1), complementary to the work of Slick et al (1999) but intended for non-cognitive assessments, that provides evidence in favour of, and against, a given diagnosis or illness, not malingering per se. The aim is to assist the court with a dispassionate, logical, sequential account of those factors that support, and those that go against, a true diagnosis, and their relative strengths; actively identifying confounders and areas of conflict, ambiguity and uncertainty; and accepting the limitations of one's knowledge and expertise. The psychiatric expert may be requested by lawyers to add scientific credibility to their client's claim for psychological injury. However, it is important for the expert to adhere to their duty of independence and resist any attempt to make the claimant's case look stronger than the objectively evaluated medical evidence permits.

Concern has been expressed, as reported by Tracy (2014), that greater awareness of a. This judgment was the subject of an unsuccessful appeal (Ali v Caton [2014]) and the appeal judgment includes transcripts of some of the expert evidence further illustrating how that evidence was tested. 
- Symptoms supporting a true diagnosis, and whether ICD-10, DSM-5 or other recognised criteria are met

- Discrepancies in the history that conflict with the diagnosis, including variation in presentation in different settings

- Discrepancies in mental state observations between, for example, how the subject was observed to present in the waiting room or when leaving the consultation and how they presented in the consultation or between, for example, reported impairment of concentration and ability to concentrate during a lengthy consultation

- The subject's response to the exploration of their previous medical history, particularly a relevant documented history which is not mentioned or about which concealment is attempted

- Relevant psychosocial issues, without assigning undue weight or causal links, e.g.: personality factors or disorder, including any antisocial traits - substance misuse - employment history and financial responsibilities past litigation

- Temporal nature of presentation, including any changes with time, and response(s) to any intervention(s)

- Any noted differences between the subject's awareness or interest in secondary losses as compared with secondary gains

- Discrepancies between the history and reported symptoms, and the objectively observed mental state

- The subject's interest in investigations and treatments as opposed to any compensation

\section{B Diagnostic evidence from psychometric testing}

- Clinical scales utilised to support a diagnosis, noting:

their general usage, validity, sensitivity and specificity in the scientific literature

- their usage in populations similar to the assessed individual, considering both mental health difficulties and social factors such as cultural background

the findings of the scale(s), including how much or little they support a diagnosis

an active reporting of limitations, confounders and cautions regarding results

- Scales utilised to assess malingering, noting:

whether a 'general', 'malingering' or neurobiological test

the evidence for the use of this scale(s) in this mental health condition, noting validity, sensitivity and specificity in the scientific literature

the evidence for the use of this scale(s) in this specific population type, noting individual demographic and cultural factors the findings of the scale(s), including how much or little it supports a diagnosis

an active reporting of limitations, confounders and cautions regarding results, including a statement on the general use and limitations of psychometry

C Diagnostic evidence from collateral and secondary information sources (where available)

- Discrepancies between reported symptoms, such as loss of appetite and loss of weight, and observations, such as nursing observation of mealtimes and recorded weight

- Discrepancies between described or reported functioning and that of independent witnesses/reports/covert surveillance

- Documentation of whether the subject was present during the interview

\section{An expert summation from $A, B$ and $C$}

- A balanced, objective summary account of those factors that are in favour and those against the illness or diagnosis, and their relative strengths

- An active consideration of the likely effect of possible diagnostic confounders and biases:

that there might be exaggeration, perseveration or transference of real symptoms

that there is a gain to the diagnosis and/or difficulty, recognising that this of itself is not evidence of malingering - a recognition, where applicable, of the dual considerations that it might be considered reasonable and appropriate to present sympathetically to professional services in light of an individual's circumstances; further, there might be countering public narratives against the type of presentation seen. A statement to the effect that the clinician has considered both of these potential biases with regard to their own practice in this case, and an affirmation that they are presenting their best account a consideration and appropriate referencing of the scientific literature, of the validity of the application of any clinical diagnosis to the specific individual seen, actively identifying any factors that might challenge this

- a consideration of individual factors that might have affected the assessment, including, but not limited to: culture, religion and gender; the relationship between the clinician and the individual; linguistic challenges, such as variation in the use of English, poor levels of English comprehension and the use of an interpreter

- An expert opinion on the plausibility of the individual's difficulties being fully accounted for by psychiatric, neurological or developmental factors

The above are put to the court in a straightforward, logical sequence to assist the court in its role of determining an individual's credibility. The likelihood of a link with any external incentive and, if it be necessary, whether there is any intended fraud and what motivates any dishonest behaviour, remain ultimately questions for the court to decide.

FIG 1 A proposed framework for use in medicolegal reports where malingering is suspected or detected.

psychometric evaluation of malingering will result in individuals being coached to 'beat' such testing. There is no good research to support this hypothesis at this time; should it occur it is likely to be more of a problem in the specific (and, to the informed examinee, identifiable) SVTs than in general tests. Nevertheless, although it is essential to discuss the rationale for such tests, guidelines advise clinicians that they have a duty to safeguard specific information that, if widely disseminated, might preclude later use.

Notwithstanding our advice that expert psychiatric witnesses should avoid the use of the term malingering, we recognise that there may 
be circumstances in which they may consider it appropriate to identify malingering. Scott $\&$ McDermott (2011), writing particularly for a North American audience about forensic report writing that addresses malingering, give an example of a criminal case of incompetency to stand trial on the basis of depressive psychosis. For those experts who do decide to take a more 'full frontal' approach to the issue, we commend their chapter, and the following quotation from their sample report illustrates the appropriate approach:

'the available evidence indicates that Mr. Grove is presently malingering his depressive symptoms in accordance with his stated purpose to avoid criminal punishment so that he can eventually be released and kill his wife. Mr. Grove has numerous inconsistencies in his presentation that are characteristic of individuals who are malingering (p. 249).

The sample report then sets out in detail the evidence for five identified inconsistencies.

\section{Conclusions}

In one sense the expert witness is let off the hook if they avoid mention of malingering; they do not have to prove malingering, nor indeed do we think that ordinarily they should attempt to do so. Even in the sort of case example described by Scott \& McDermott (2011) it would be possible to present the evidence without using the term 'malingering'. Harking back to Lipman (1962), we argue that, just as the act of malingering is not necessarily a binary present/absent phenomenon, but interfaces degrees of intentional deception and gain, the same is true for its detection, with findings occurring on a continuum of clinical plausibility. Our criteria aim to assist the court, through a best-effort expert clinical account of the individual, by walking up to the door, but stopping short of detecting malingering and usurping the role of the judge or trier of the facts. This is because it is the role of the court to determine an individual's credibility and, if it be necessary, what motivates any dishonest behaviour. The role of the expert is to do no more than assist this process.

\section{References}

American Psychiatric Association (2000) Diagnostic and Statistical Manual of Mental Disorders (4th edn rev) (DSM-IV-TR). APA.

American Psychiatric Association (2013) Diagnostic and Statistical Manual of Mental Disorders (5th edn) (DSM-5). APA.

Black DW (2015) The natural history of antisocial personality disorder. Canadian Journal of Psychiatry, 60: 309-14.

Criminal Practice Directions [2015] EWCA Crim 1567.

Eyre G, Alexander L (2015) Writing Reports in Civil Claims: An Essential Guide. Professional Solutions Publications.
Grieve R (2012) The role of personality, psychopathy, and previous experience with assessment in intentions to fake in psychological testing. Current Psychology, 31: 414-22.

Hall RC, Hall RC (2006) Malingering of PTSD: forensic and diagnostic considerations, characteristics of malingerers and clinical presentations. General Hospital Psychiatry, 28: 525-35.

Heilbronner RL, Sweet JJ, Morgan JE, et al (2009) American Academy of Clinical Neuropsychology Consensus Conference Statement on the neuropsychological assessment of effort, response bias, and malingering. Clinical Neuropsychologist, 23: 1093-129.

Hickling EJ, Blanchard EB, Mundy E, et al (2002) Detection of malingered MVA related posttraumatic stress disorder: an investigation of the ability to detect professional actors by experienced clinicians psychological tests and psychophysiological assessment. Journal of Forensic Psychology Practice, 2: 33-54.

Judicial Studies Board (2010) Crown Court Bench Book: Directing the Jury. JSB.

Lambert MT, Bonner J (1996) Characteristics and six-month outcome of patients who use suicide threats to seek hospital admission. Psychiatric Services, 47: 871-3.

Lipman FD (1962) Malingering in personal injury cases. Temple Law Quarterly, 35: 141-62.

McDermott BE, Dualan IV, Scott CL (2013) Malingering in the correctional system: does incentive affect prevalence? International Journal of Law and Psychiatry, 36: 287-92.

Millis SR, Putnam SH (1996) Evaluation of malingering in the neuropsychological examination of mild head injury. NeuroRehabilitation, 7: 55-65.

Nies KJ, Sweet JJ (1994) Neuropsychological assessment and malingering: a critical review of past and present strategies. Archives of Clinical Neuropsychology, 9: 501-52.

Peace KA, Masliuk KA (2011) Do motivations for malingering matter? Symptoms of malingered PTSD as a function of motivation and trauma type. Psychological Injury and Law, 4: 44-55.

Scott C, McDermott B (2011) Malingering. In The Psychiatric Report: Principles and Practice of Forensic Report Writing (eds A Buchanan, MA Norko): 240-53. Cambridge University Press.

Slick DJ, Sherman EM, Iverson GL (1999) Diagnostic criteria for malingered neurocognitive dysfunction: proposed standards for clinical practice and research. Clinical Neuropsychology, 13: 545-61.

Tracy DK (2014) Evaluating malingering in cognitive and memory examinations: a guide for clinicians. Advances in Psychiatric Treatment, 20: 405-12.

Tracy DK, Rix KJB (2017) Malingering mental disorders: clinical assessment. BJPsych Advances, 23: 27-35.

World Health Organization (1992) The ICD-10 Classification of Mental and Behavioural Disorders: Clinical Descriptions and Diagnostic Guidelines. WHO.

\section{Cases}

Ali v Caton \& Motor Insurers Bureau [2013] EWHC 1730 (OB).

Ali v Caton [2014] EWCA Civ 1313

Daubert v Merrell Dow Pharmaceuticals (1993) 509 US 579

Edwards v Martin [2010] EWHC 570 (QB).

$R v$ Dlugosz and Others [2013] EWCA Crim 2.

R v MacKenney [2004] 2 Cr App R 32.

SF v Quarriers [2015] CSOH 82.

Turner \& Turner v Jordan \& Motor Insurers Bureau [2010] EWHC 1508 (QB).

US v Scheffer (1998) 523 US 503.
MCO answers

$\begin{array}{lllll}1 \mathrm{a} & 2 \mathrm{~b} & 3 \mathrm{a} & 4 \mathrm{e} & 5 \mathrm{~d}\end{array}$ 
MCQs

Select the single best option for each question stem

1 Factors associated with malingering include:

a a history of past litigation

$\mathrm{b}$ a relative with the condition in question

c a lower 10

$d$ a history of childhood abuse

e previous psychiatric in-patient admissions.

\section{Factors that can limit a clinician's} detection of malingering include:

a selection bias

b confirmatory bias

c a poor clinical rapport

$d$ use of psychometric scales

e no previous contact with the individual.
3 The most important property of a psychometric test of which the medical expert should be cognizant is:

a its margin of uncertainty or error

$b$ its country of origin

c the time taken to complete testing

$d$ the ability of a court or jury to understand its findings

e whether or not it is completed in a forensic setting such as a prison.

4 Malingering is:

a a medical illness

b a legal term

c a psychological model

d a prejudicial insinuation

e just an ordinary English word.
5 The role of the medical expert is:

a dependent on the patient's condition or complaint

b to determine the likelihood of a link between symptoms and external incentive(s)

c to prove or disprove that an individual is malingering

$d$ to report on the plausibility of an individual's symptoms

e to ascertain any psychological motivation for dishonesty. 